\title{
POLYSACCHARIDE DETERMINATION IN CORN SILK WITH 3,5-DINITROSALICYLIC ACID COLORIMETRY
}

\author{
Bing Li, Yaping Li, Hongli Zhou* \\ College of Chemical and Pharmaceutical Engineering, Jilin Institute of Chemical Technology Chengde Street, Jilin City, China. \\ *Corresponding Author Email: zhl67@126.com
}

This is an open access article distributed under the Creative Commons Attribution License, which permits unrestricted use, distribution, and reproduction in any medium, provided the original work is properly cited.

\section{ARTICLE DETAILS}

Article History:

Received 26 June 2018 Accepted 2 July 2018

Available online 1 August 2018

\section{ABSTRACT}

Contents of reducing sugars in crude polysaccharides from corn silk were measured by 3,5-dinitrosalicylic acid (DNS) colorimetry with incident wavelength at $492 \mathrm{~nm}$, amount of DNS $=1.5 \mathrm{~mL}$, coloration temperature at $90^{\circ} \mathrm{C}$ and coloration time $=7 \mathrm{~min}$. The standard curve equation of glucose was $\mathrm{y}=3.9163 \mathrm{x}-0.0292$; the glucose solubility ranged from 0.07332 to $0.25662 \mathrm{mg} / \mathrm{ml}$, and the absorbance and glucose content were well linearly related. The DNS colorimetry was outstanding with easiness, fast speed, accuracy, safety, low cost, high stability and reproducibility. The polysaccharide content in the cornstarch (reducing sugar) was $18.16 \%$.

\section{KEYWORDS}

Corn silk, 3,5-Dinitrosalicylic acid, Colorimetry, Polysaccharides.

\section{INTRODUCTION}

Corn silk tastes light and has mild effects of clearing blood heat, diuretics, liver calming, and cholagogue. Corn silk can treat diabetes, jaundice, measles, celiac hematuria, blood collapse and other symptoms [1]. The rich source, low price and easy collection make corn silk a medicinal resource with broad research and development prospects. The major corn silk polysaccharides include glucose, galactose, arabic sugar, galactose, mannose and xylose [2].

Wang Liming used an anthrone sulfate method to measure tea polysaccharides and optimized the conditions as follows: ketone concentration $=0.05 \%$, ratio of sample solution to anthrone-sulfuric acid $=1: 4$, reaction time of $5 \mathrm{~min}$ at $100{ }^{\circ} \mathrm{C}$, immediate cooling in ice water for $30 \mathrm{~min}$, and absorbance at $675 \mathrm{~nm}$ [3]. This method was highly reproducible with the average recovery of $94.58 \% \pm 1.68 \%$ and relative standard deviation (RSD) of $0.548 \%$ [3]. Gao Lijun et al. detected polysaccharides in Radix Cynanchi Auriculati by using a phenol- sulfuric acid method and found the absorbance at $490 \mathrm{~nm}$ was well linearly related with the measured content in the range of 8-64 $\mu \mathrm{g}$, with the average recovery rate of $100.9 \%$ [4]. This method is simple and accurate with high linearity [4].

Wang Hongying et al. used 3,5-dinitrosalicylic acid (DNS) colorimetry to measure polysaccharides in Ophiopogon japonicas and confirmed this method was simple, easy-to- implement, and reproducible. DNS colorimetry can be used as a routine method to detect polysaccharide contents in Ophiopogon japonicus [5]. Zhang Lihua et al. used the DNS method to measure the reducing sugar and total sugar in AGP and calculated the total polysaccharide content. The method is sensitive, stable and reproducible, which contribute to the study of quality control method of AGP [6]. Hu Xijie et al. optimized the parameters as follows: wavelength at $495 \mathrm{~nm}$, and VDA: V $=1.5: 3.5$, reaction temperature at $90^{\circ} \mathrm{C}$, and time of reaction $=5-7 \mathrm{~min}$ and found the method was efficient, accurate and stable in determining reducing sugars [7]. In the present article, we discussed the parameters of DNS colorimetry to detect reducing sugar in corn silk.

\section{EXPERIMENTAL CONDITIONS}

\subsection{Experimental Instruments and Equipment}

A ultraviolent (UV) grating spectrophotometer (752N, Shandong Gaomi Rainbow Analysis Instrument Co., Ltd.), a UV visible light photometer (TU1810, Beijing General Analysis Equipment Co., Ltd.), and an analytical balance (FA2004, Shanghai Fine Technology Instrument Factory) were used.

\section{$2.2 \quad$ Raw materials and reagents}

Corn silk (collected in 2016 from the suburbs of Jilin City), phenol (Tianjin Ruijinte Chemicals Co., Ltd., 20060617), glucose (Tianjin Damao Chemical Reagent Factory, 20010724), potassium sodium tartrate (Beijing Chemicals Factory, 20010705), DNS (Sinopec Group Chemical Reagent Co., Ltd., F20080403), NaOH (Tianjin Northern Tianyi Chemical Reagent Factory, 20010308), and anhydrous sodium sulfite (Zhejiang Yongjia County Chemical Reagent Factory, 890311) were used.

\section{PROCEDURES AND METHODS}

\subsection{Reagent configuration}

Glucose control stock solution was prepared as follows: $0.1004 \mathrm{~g}$ of anhydrous glucose was completely dissolved to a volume of $100 \mathrm{~mL}(1.004$ $\mathrm{mg} / \mathrm{mL}$ ). Glucose standard solution preparation was prepared as follows: $0,1,2,3,4,5,6$ and $7 \mathrm{~mL}$ of the above stock solution were aspirated and set in 25-mL volumetric flasks for use [8].

DNS rendering liquid was prepared as follows: $6.3 \mathrm{~g}$ of DNS and $262 \mathrm{~mL}$ of a $2 \mathrm{M} \mathrm{NaOH}$ solution were added to $500 \mathrm{~mL}$ of a hot aqueous solution containing $185 \mathrm{~g}$ of sodium potassium tartrate. Then $5 \mathrm{~g}$ of crystalline phenol and $5 \mathrm{~g}$ of sodium sulfite were added. After stirring, the solution was cooled and diluted to a constant volume of $1000 \mathrm{~mL}$. The solution was stored in a brown bottle for use [9]. 
crude polysaccharides of corn silk were investigated using the DNS colorimetry [10].

\subsubsection{Maximum absorption wavelength of the screening}

To $1.5 \mathrm{~mL}$ of the DNS solution in a test tube, $2 \mathrm{~mL} 0.28112 \mathrm{mg} / \mathrm{mL}$ glucose standard solution was added under shaking. The solution was placed in a boiling water bath and heated for $5 \mathrm{~min}$, removed, and quickly cooled to room temperature with tap water. The solution was diluted to $10 \mathrm{~mL}$ with distilled water and allowed to stand for more than $20 \mathrm{~min}$. The DNS was zeroed and the absorbance within 350-650 nm was scanned and measured.

\subsubsection{Selection of developer amount}

The glucose standard solution $(0.28112 \mathrm{mg} / \mathrm{mL})$ was used to select the amount of DNS. Firstly, $2 \mathrm{~mL}$ of glucose standard solution was accurately weighed and added into 7 tubes respectively. Then $0.6,0.9,1.2,1.5,1.8$, 2.1 , or $2.4 \mathrm{~mL}$ of DNS was added to test tubes. The steps were the same as in section 2.2.1. Finally, the volume was adjusted with distilled water. Absorbance was measured in a $25 \mathrm{~mL}$ volumetric flask.

\subsubsection{Selection of Coloration Temperature}

To 5 test tubes, each was added with $2 \mathrm{~mL}$ of the $0.16064 \mathrm{mg} / \mathrm{mL}$ glucose standard solution and $1.5 \mathrm{~mL}$ of DNS to make the reaction systems develop color at $60,70,80,90$, and $100{ }^{\circ} \mathrm{C}$ respectively. The steps were the same as in section 2.2.1. Finally, the tubes were diluted with distilled water to a $25 \mathrm{~mL}$ volumetric flask for measurement of absorbance.

\subsubsection{Selection of Color Rendering Time}

To 6 test tubes, $2 \mathrm{~mL}$ of the $0.16064 \mathrm{mg} / \mathrm{mL}$ glucose standard solution and $1.5 \mathrm{~mL}$ of DNS were added, followed by color development for $3,5,7,10$, 15 and 20 min respectively. The steps were the same as section 2.2.1, and the reaction temperature was $90^{\circ} \mathrm{C}$. The tubes were diluted with distilled water into a $25 \mathrm{~mL}$ volumetric flask for absorbance measurement.

\subsection{Preparation of glucose standard curve}

To a test tube, $2 \mathrm{~mL}$ of each concentration of the glucose standard solution was pipetted, and $1.5 \mathrm{~mL}$ of DNS was added under shaking, followed by placement in a $90{ }^{\circ} \mathrm{C}$ water bath and heating for $7 \mathrm{~min}$. Then the tube was removed, quickly cooled to room temperature with tap water, and diluted to $10 \mathrm{~mL}$ with distilled water. After placement for more than $20 \mathrm{~min}$, the absorbance was measured.

\subsection{Stability Experiment}

The procedure was the same as in section 2.3. The solutions were removed after optimization for 20,30, 40, or $50 \mathrm{~min}$. Absorbance was measured after 1 and $2 \mathrm{~h}$.

\subsection{Precision Experiment}

To 5 test tubes, $2 \mathrm{~mL}$ of the $0.16064 \mathrm{mg} / \mathrm{mL}$ glucose standard was added following the same steps as in section 2.3. After the parameters were optimized, the absorbance was measured after $30 \mathrm{~min}$ and the RSDs were calculated.

\subsection{Repeatability Experiment}

Two clean test tubes were taken at different time periods and added with the $0.16,064 \mathrm{mg} / \mathrm{mL}$ polysaccharide solution and then $1.5 \mathrm{~mL}$ of DNS. The procedure was the same as in section 2.3 , and the absorbance was measured under the optimized parameters. A total of 5 absorbance values were measured and RSDs were calculated.

\subsection{Recovery experiment}

Five control substances with glucose levels from 0.1 to $0.26 \mathrm{mg} / \mathrm{mL}$ were set up and measured under the optimized conditions.

\subsection{Sample recovery experiment}

To 6 clean test tubes, each was accurately pipetted with $1.0 \mathrm{~mL}$ of the sample solution containing $0.06976 \mathrm{mg} / \mathrm{mL}$ polysaccharide and added with $1.5 \mathrm{~mL}$ of DNS. Every $1 \mathrm{~mL}$ of glucose standard solution, with concentration of $0.03665,0.05499,0.07328 \mathrm{mg} / \mathrm{mL}$, was measured by the assay and the RSDs were calculated.

\subsection{Determination of polysaccharide content}

\subsubsection{Measurement of Total Polysaccharide Content in Corn Silk}

Net content of total polysaccharides in the crude corn silk was measured using the phenol-sulfuric acid method.

\subsubsection{Detection of reducing sugar content in crude polysaccharides}

To two tubes, each was added with $2 \mathrm{~mL}$ of crude polysaccharide solution $(2.03 \mathrm{mg} / \mathrm{ml})$, and the blank was added with $2 \mathrm{~mL}$ of distilled water. The absorbance (A) was measured under the condition of section 2.3.

\section{RESULTS}

\subsection{Conditions for polysaccharide content measurement}

\subsubsection{Determination of absorption wavelength}

The DNS solution was zeroed and scanned with a UV spectrophotometer (Figure 1.a). The maximum absorption wavelength should be $\lambda_{\max }=$ $492 \mathrm{~nm}$. The curve of the glucose content versus the absorbance was plotted. Finally, the appropriate range of measuring reducing sugar was determined.

\subsubsection{Effect of optimal amount of color reagent}

The amount of DNS was related to the content of reducing sugar in the test solution. When the amount of DNS was less than $1.5 \mathrm{~mL}$, the absorbance of the solution was intensified with the increase of DNS amount (Figure 1.b). When the amount of DNS was larger than $1.5 \mathrm{~mL}$, the absorbance decreased slightly. The optimal amount of DNS was $1.5 \mathrm{~mL}$.

\subsubsection{Effect of color temperature}

The DNS reacted slowly with reducing sugars at normal temperature and did not even react chemically. In the five reaction temperatures, the general effect was better at higher temperature. The absorbance maximized at $90^{\circ} \mathrm{C}$, but slightly decreased at $100^{\circ} \mathrm{C}$ (Figure 1.c). This may be because the solution volatilized at too high temperature, which affected the total volume of the reaction and thus its absorbance.

\subsubsection{Effect of color rendering time}

In the first $6 \mathrm{~min}$, DNS absorbed rapidly due to its rapid reduction (Figure 1.d). After $7 \mathrm{~min}$ of color development, the absorbance began to change gently or slightly decreased. In other words, the color development time can be $7 \mathrm{~min}$.
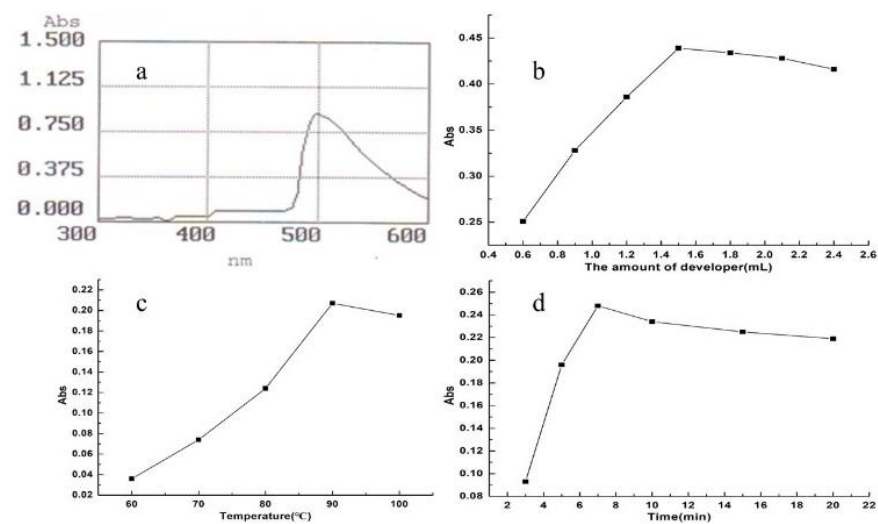

Figure 1: Influences of measurement conditions

\subsection{Glucose standard curve}

With the glucose concentration as the $\mathrm{X}$-axis and the absorbance as the $\mathrm{Y}$ axis, the standard curve was plotted according to the actual calculated glucose absorbance. The regression equation for the standard curve was $y$ $=3.9163 \mathrm{x}-0.0292\left(\mathrm{R}^{2}=0.9981\right)$. Experiments showed the glucose concentration ranged from 0.07332 to $0.25662 \mathrm{mg} / \mathrm{mL}$, and the absorbance and glucose content were well linearly related (Figure 2). 


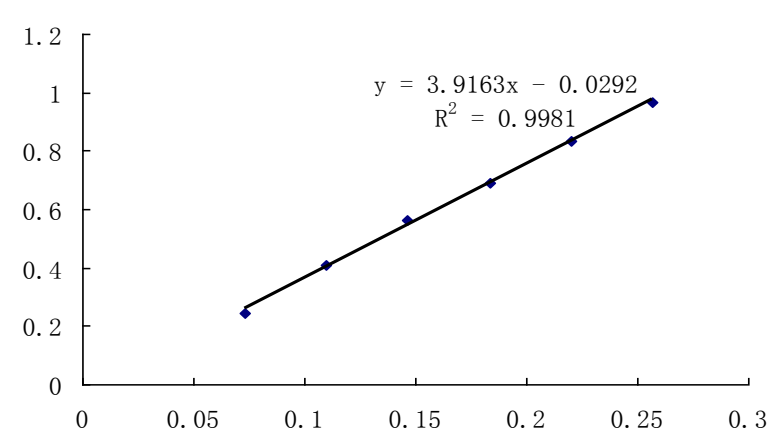

Figure 2: Standard glucose absorbance - content curve

4.3

\section{Stability test results}

The absorbance values measured after $20 \mathrm{~min}, 30 \mathrm{~min}, 40 \mathrm{~min}, 50 \mathrm{~min}, 1$ $\mathrm{h}$, and $2 \mathrm{~h}$ were $0.408,0.412,0.413,0.414,0.414$ and 0.417 , respectively.
RSD $=0.66 \%<1 \%$ indicates high stability in $20-120 \mathrm{~min}$.

\subsection{Precision Experiment Results}

The absorbances of five identical samples were $0.409,0.409,0.406,0.412$ and 0.404 , respectively. $\mathrm{RSD}=0.755 \%<1 \%$ suggest high precision.

\subsection{Repeatability Test Results}

The absorbances of the five replicates were $0.400,0.414,0.400,0.404$ and 0.393 , respectively. $\mathrm{RSD}=0.16 \%<1 \%$ indicates the standard product had high repeatability.

\subsection{Recovery Test Results}

In the range of $0.1-0.26 \mathrm{mg} / \mathrm{mL}$, the recovery rate increased as the amount of sugar increased (Table 1 ). The average recovery rate exceeded $98 \%$. Therefore, the experimental method has high accuracy.

Table 1: Recovery experiment

\begin{tabular}{|lllllll|}
\hline Test group & $\begin{array}{l}\text { Absorbance } \\
\text { A }\end{array}$ & $\begin{array}{l}\text { Amount of sugar } \\
\text { measured } \\
(\mathrm{mg} / \mathrm{mL})\end{array}$ & $\begin{array}{l}\text { Actual } \\
\text { amount } \\
(\mathrm{mg} / \mathrm{mL})\end{array}$ & $\begin{array}{l}\text { sugar } \\
\text { Recovery } \\
\text { rate(\%) }\end{array}$ & $\begin{array}{l}\text { Average } \\
\text { recovery } \\
(\%)\end{array}$ & rate \\
\hline 1 & 0.407 & 0.10977 & 0.10998 & 99.8 & & 1.46 \\
2 & 0.562 & 0.15095 & 0.14664 & 102.9 & 100.4 & \\
3 & 0.692 & 0.18415 & 0.1833 & 100.5 & & \\
5 & 0.832 & 0.2199 & 0.21996 & 100.0 & & \\
\hline
\end{tabular}

$\mathrm{RSD}=0.16 \%<1 \%$ suggests the standard product has high repeatability.

Table 2: Sample Recovery Test $(\mathrm{n}=6)$

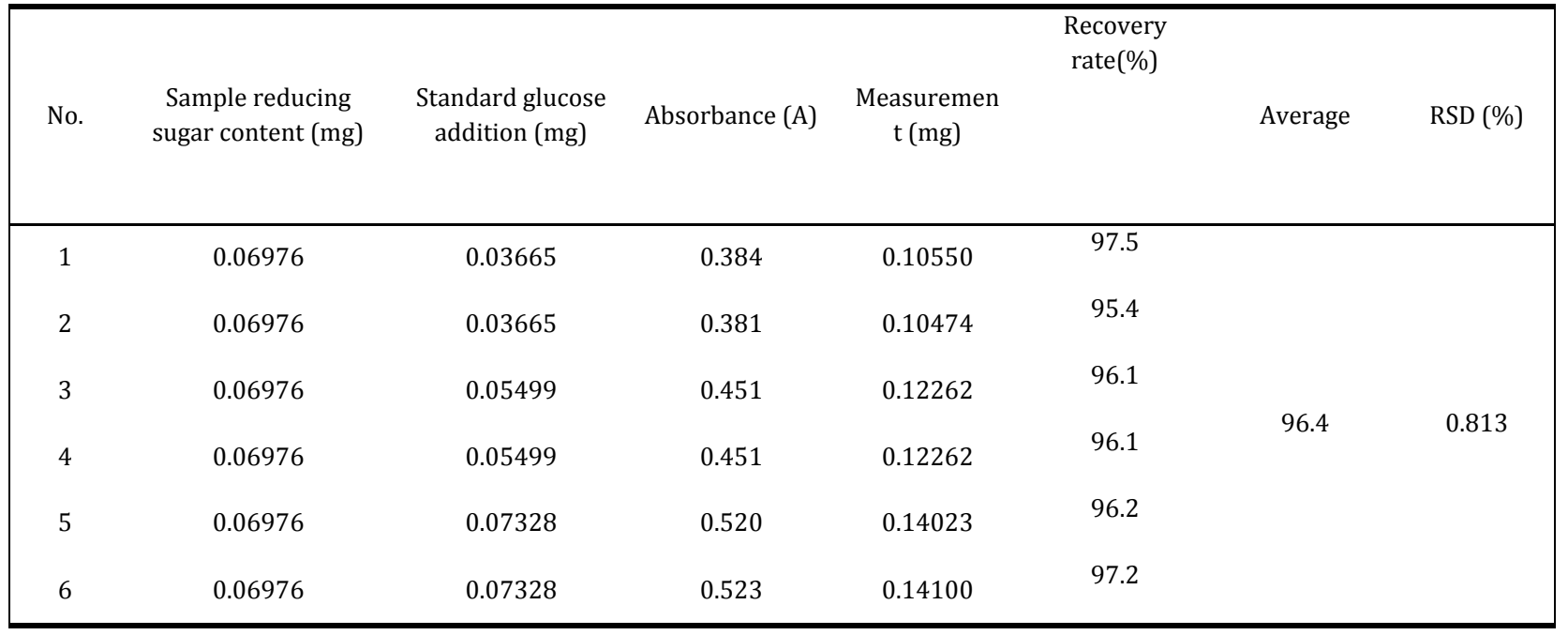

$\mathrm{RSD}=0.813 \%<1 \%$ indicates high sample recovery.

\subsection{Polysaccharide content results}

The total polysaccharide content, reducing sugar content and polysaccharide content in the crude corn silk were $26.3 \%, 8.14 \%$ and $18.16 \%$, respectively.

\section{CONCLUSIONS}

The DNS colorimetry is convenient, safe, accurate and cheap, and can be used to measure the reducing sugar in corn silk. The optimal measurement conditions were wavelength at $492 \mathrm{~nm}$, amount of DNS $=1.5 \mathrm{~mL}$, and color development time $=7 \mathrm{~min}$. The total polysaccharide content in waterextracted alcohol-coarse corn measured by the sulfuric acid-phenol method was $26.3 \%$. The content of reducing sugar was $8.14 \%$ and polysaccharide content was $18.16 \%$ detected by DNS colorimetry. The first application of DNS colorimetry to detect the reducing sugar of corn silk has high significance for promoting the development of corn silk polysaccharides and provides scientific basis for improving the quality standards of corn silk polysaccharides. 


\section{ACKNOWLEDGMENTS}

This study was financed by Jilin provincial development and Reform Commission (Grant No. 2017C044).

\section{REFERENCES}

[1] Liu, J., Yang, G., Han, X.Q. 2005. Polysaccharides extraction from Stigma Maydis and its assaying method [J]. Heilongjiang Medicine \& Pharmacy.

[2] Li, B., Cui, Z., Zhao, Y. 2008. Study on the Preparation and Composition of Polysaccharide in Corn Silk [J]. Academic Periodical of Farm Products Processing.

[3] Wang, L.M., Xia, W.S. 2005. Determination of TPS by Improvement of Anthrone-sulfuric Acid Method [J]. Food Science.

[4] Gao, L.J., Wang, H.Z., Cui, J.H. 2004. Studies on the Extraction Technology of Soluble Polysaccharides from Radix Cynanchum bungee [J]. Food Science, 25 (10), 178-180.

[5] Wang, H.Y., Qian, S., Zhao, Q.C. 2005. Determination of Polysaccharide in Ophiopogon japonicus with 3,5-Dinitrosalicylic Acid Colorimeitry [J]. Journal of Shenyang Agricultural University, 36 (5), 628-630.
[6] Zhang, L.H., Zhang, L.P., Jin-Qun, H.U. 2008. Quantitative Detemination of AGP by DNS Method [J]. Chinese Journal of Information on Traditional Chinese Medicine.

[7] Xi-Jie, H.U., Xiao, J.H., Yu, X. 2005. Studies on the optimal conditions for measurement of reduced sugar in a 3,5-dinitrosalicylic acid colorimetry [J]. Acta Academiae Medicinae Zunyi.

[8] Garg, D.K., Goyal, R.N. 1992. Hematological and hepatotoxic effects of silken styles of corn in albino rats. Journal of Applied Toxicology, 12 (5), 359-365.

[9] Liu, D.S., Shen, Q., Wang, Z.X. 2004. Study on the Preparation of Cellulose/Poly (ethylene glycol)/Vitamin Drug Membrane and Its Release Property [J]. Journal of Cellulose Science and Technology, 12 (3), 25-30.

[10] Wang, J.G., Zhang, S.Z., Yang, B.P. 2008. Application of 3,5Dinitrosalicylic Acid (DNS) Method to Test the Reducing Sugar and Watersoluble Total Sugar Content in Sugarcane Internodes[J]. Sugarcane and Canesugar.

[11] He, Y.T., Gao, H.N., Xu, Y.X. 2012. Chemical Analysis and Antioxidant Activities In Vitro of Polysaccharide Extracted from Corn Silk [J]. Advanced Materials Research, 535-537, 2335-2339. 